\title{
Solution of spread, prevention, cure and logistic methods for ebola virus infection based on mathematical model
}

\author{
Ma Yanlin ${ }^{1, a}$, Yang Wuyue ${ }^{1, b}$ and Zhao xuan ${ }^{1, c}$ \\ ${ }^{1}$ Beijing Forestry University,Beijing,China \\ aemail, ${ }^{\mathrm{b}}$ email, ${ }^{\mathrm{c} e m a i l}$
}

Keywords: ebola virus infection ,logistic methods,spread

\begin{abstract}
As the requirements of the question, all study we have done is about EVD pathology, characteristic of EVD spread, and set up EVD spread model and medical production logistic optimal model which are based on these knowledge. By using traditional epidemic model with innovation of considering the population age structure as part of the model, we solved the first model which mentioned above. The model is able to combine the patients contagious distribution with age distribution in mathematical way,thus people can know more about the epidemic trend of EVD. Setting up transfer stations is our way to solve the second model. Drugs get into transfer stations ,then divided into every patients' homes. The transfer stations are set up according to the location of airport. We divided them into large-scale ,middle-scale and small-scale transfer stations. The drugs are delivered according to the size of stations decreasing step by step so that people can keep the transport order , save energy as well as refrain from disturbing the airline. Picking out the line and ensuring the location of transfer stations are our main problems. Shortest path problem model and the transportation linear programming .Model is the tool to solve the problems. We hope our models can have a little effect on EVD prevention and treatment, so as to controlling the disease spreading.
\end{abstract}

\section{Introduction}

Ebola virus disease (EVD) was first identified in 1976,in two simultaneous outbreaks in Sudan and the Democratic Republic of the Congo.It is not completely understood why this epidemic has expanded to such an unprecedented scale compared to previous outbreaks,although regional instability,urbanization,and lack of capacity have all been suggested as potential factors. EVD is transmitted by contact with body fluids.Healthcare workers are at particular risk for transmission due to their frequent contact with patients and body fluids,and burial ceremonies in which mourners contact the body of the deceased have also been identified as playing an important role in transmission.Ebola has an average incubation period of 8-10days (with a range of 2-21 days),and infectiousness is believed to coincide with symptom onset.EVD progresses in two broad stages.Symptoms in the first stage often include fever,headache,sore throat,fatigue,and muscle pain,and the first stage can often be mistaken for other diseases,such as malaria or includes more intense symptoms such as vomiting,diarrhea,rash,symptoms of impaired kidney from the first stag,with much higher death rates in the second stage (indeed,in some outbreaks all second-stage patients died).As second stage symptoms tend to have more release of body fluids (e.g vomit or diarrhea),transmissibility is likely to be higher as the disease progresses as well.Accounting for the stage structure is thus particularly important when evaluating healthcare capacity and how the timing of hospitalization may affect the outbreak dynamics. ${ }^{[1]}$

First established the epidemiological model age structure is F.Hoppensteadt ${ }^{[7]}$ Since then, Epidemiological model of the age structure of emerging. Most scholars discussing the model of SIS, SIR, and SEIR, Yao Yong ${ }^{[6]}$ Introduces the SEIR model with age structure, And discusses the stability of the disease-free equilibrium solution. ${ }^{[13-14]}$ Most of them do not take into account the influence of age on the patient's illness disease. 


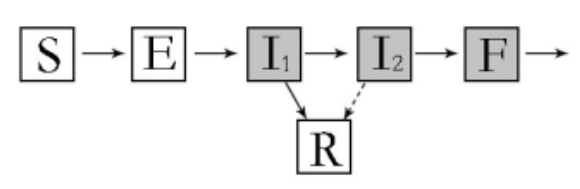

Figure 1 . The flow chart from [1].

\section{Restatement and clarification of the problem}

The definition of space debris.This article aims to build a mathematical model about prevention and spread trend,based on the regularity of spread and speed of spread .

Disease spread description

Logistical method and destinations certification

Modeling.Set up spread model according to the detailed data of different region (different density of population )which was provided by WHO and build up a age structure-infection model which is based on the traditional infection model,so that we can establish the optimizing model of drug production quantity and targeted drug delivery.That is setting up intermediate of transport according to the condition of different regions and ensure the quantity of drug transit. 


\section{Explain assumptions and rationale/justification}

\section{Model 1:}

1.Without considering births, deaths, population dynamics factor mobility, etc. This means considering a closed environment and assuming disease over time than birth, death is much significant change over time, so that the latter can be neglected. Thus, the total population of this environment remains a constant, $N(t) \equiv K$ or $S(t)+I(t)+R(t) \equiv K$.

2. Once a patient in contact with the susceptible necessarily have some infectivity. It is assumed that at time $t$ within the unit of time, the number of susceptible and can infect a patient susceptible total number within this environment, $S(t)$ proportional to the scale factor is $\beta$, Thus in unit time at time $t$ is the number of people infected by sick is $\beta S(t) I(t)$.

\section{Model 2:}

1. airport location is where the station is, the demand of medical productions increases with the increase of the amount of patients around the zone.

2.the distance from stations to each patient is not far, thus the delivery cost from station to patients is not under consideration.

3.the medical production could only be transferred directly from manufacture to high medical transfer stations, and directly from high to middle, and then from middle to small. It is banned to deliver across this level structure.

4.the candidate locations of each station is assumed to be known for discrete network selecting location.

5.the cost of delivery is simply linear positive correlative with the distance.

6.all stations is capable of handling the delivery process.

\section{models}

\section{Model 1}

\section{Model structure}

This model, taking into account the different stages have different infection rates,Ebola often progresses through multiple stages of illness - an initial infectious stage in which symptoms tend to by milder (such as fever, headache, sore throat, muscle aches), often progressing to diarrhea, vomiting, and a second, more intense stage during which the more advanced symptoms (such as hemorrhaging and multi-organ failure) manifest [1,3,7], The second stage is usually fatal.This model is based on SIR model, We also consider the age structure, We divided the total population: $S(a, t)$ is susceptible, $E(a, t)$ is expose, $R(a, t)$ is removal, $I(a, b, t)$ is infective .Assume $N(a), 0 \leq a \leq A$ as populatio $\mathrm{n}$ density function depend on age. $a, b$ represent the physiological age and infected age separately, and $A$ is the maximum physiological age a individual could live with. $R$ represents the cured group of people, and they have the immunity of ebola virus infection.

Table1. Variables and their meanings

\begin{tabular}{|l|l|}
\hline Variable & Meanings \\
\hline$S$ & The fraction of the population which is susceptible \\
\hline$E$ & The fraction exposed \\
\hline$I_{1}$ & The population in the first stage of infection \\
\hline$I_{2}$ & The second stage of infection \\
\hline$R$ & The fraction of the population which who are recently recovered \\
\hline$F$ & The fraction of the population who hace died \\
\hline
\end{tabular}

Ebola virus infection equation: 


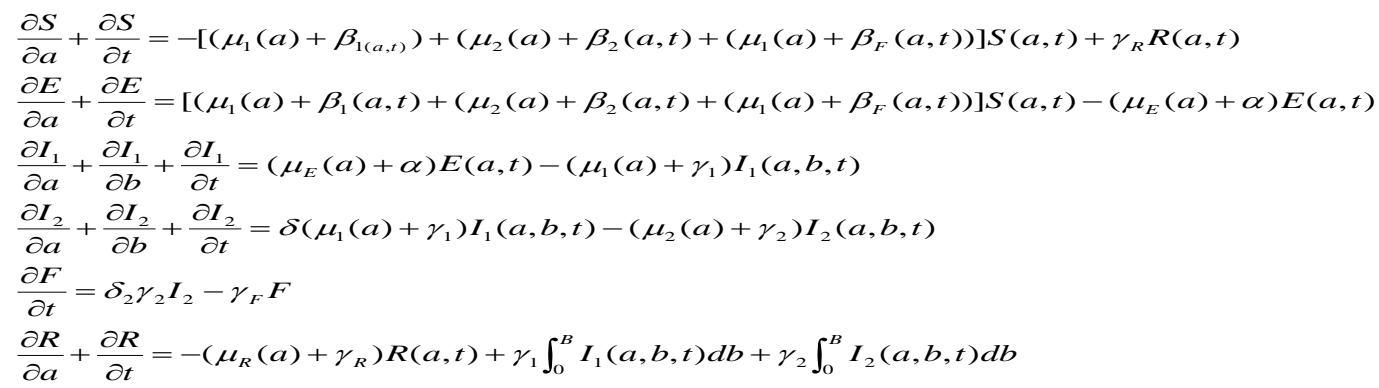

\section{Parameter Estimation}

Table2.From

Wikipedia http://en.wikipedia.org/wiki/List_of_countries_and_dependencies_by_population

\begin{tabular}{|l|l|l|l|l|}
\hline National & Population & Information Date & Proportion & Source \\
\hline Guinea & $9,982,000$ & 2010 & $0.14 \%$ & UN estimate for 2010 \\
\hline Liberia & $3,994,000$ & 2010 & $0.06 \%$ & UN estimate for 2010 \\
\hline Sierra leone & $5,868,000$ & 2010 & $0.08 \%$ & UN estimate for 2010 \\
\hline
\end{tabular}

Table3.This data source [1]

\begin{tabular}{|c|c|c|c|c|}
\hline & Meaning & Units & Range & Source \\
\hline$\beta_{1}$ & The first phase of the prevalence & 1/people.day & Estimated & Estimated \\
\hline$\frac{\beta_{2}}{\beta_{1}}$ & $\begin{array}{l}\text { The prevalence ratio of the second phase } \\
\text { vs. first stage of the prevalence }\end{array}$ & Unitless & $1.5-5$ & {$[8,9]$} \\
\hline$\frac{\beta_{F}}{\beta_{1}}$ & $\begin{array}{l}\text { The prevalence ratio of the funeral } \\
\text { transmission vs first stage of the } \\
\text { prevalence }\end{array}$ & Unitless & $1.5-5$ & {$[8,9,10]$} \\
\hline$\alpha^{-1}$ & The average incubation period & Days & $8-10$ & {$[2,5]$} \\
\hline$\gamma_{1}^{-1}$ & The first phase of the cycle of illness & Days & $5-7$ & {$[2,3]$} \\
\hline$\gamma_{2}^{-1}$ & The second phase of the cycle of illness & Days & $1-2$ & {$[2,3]$} \\
\hline$\gamma_{F}^{-1}$ & Time from death until burial & Days & $1-3$ & {$[2,4]$} \\
\hline$\gamma_{R}^{-1}$ & $\begin{array}{l}\begin{array}{l}\text { From recovery to the time spent } \\
\text { susceptible }\end{array} \\
\end{array}$ & Days & $5-15$ & {$[5], *$} \\
\hline$\delta$ & Total mortality & Unitless & Estimated & Estimated \\
\hline$\delta_{2}$ & The second phase of mortality & Unitless & $0.9-1$ & {$[3]$} \\
\hline
\end{tabular}

Table4.This data source ${ }^{[1]}$

\begin{tabular}{|l|l|l|l|}
\hline & Parameter & Best estimate & Range of LHS Estimates \\
\hline \multirow{4}{*}{ All Countries } & $\beta_{1}$ & 0.11 & $0.079-0.18(0.12)$ \\
\cline { 2 - 4 } & $\delta$ & 0.56 & $0.55-0.6(0.57)$ \\
\cline { 2 - 4 } & $R_{0}$ & 1.6 & $1.43-1.64(1.53)$ \\
\hline \multirow{5}{*}{ Guinea } & $\beta_{1}$ & 0.16 & $0.078-0.18(0.11)$ \\
\cline { 2 - 4 } & $\delta$ & 0.65 & $0.64-0.72(0.68)$ \\
\cline { 2 - 4 } & $R_{0}$ & 1.79 & $1.47-1.79(1.61)$ \\
\hline \multirow{3}{*}{ Liberia } & $\beta_{1}$ & 0.12 & $0.0725-0.17(0.10)$ \\
\cline { 2 - 4 } & $\delta$ & 0.63 & $0.63-0.72(0.67)$ \\
\cline { 2 - 4 } & $R_{0}$ & 1.81 & $1.34-2.75(1.47)$ \\
\hline \multirow{3}{*}{ Sierra Leone } & $\beta_{1}$ & 0.12 & $0.085-0.17(0.12)$ \\
\cline { 2 - 4 } & $\delta$ & 0.38 & $0.36-0.38(0.37)$ \\
\hline
\end{tabular}




\begin{tabular}{|l|l|l}
\hline$R_{0}$ & 1.32 & $1.39-1.37(1.25)$
\end{tabular}

Fitting and forecasting resultsBecause we did not find data on the age structure is changing infection rate, We did not have to carry out further graphical analysis.

\section{Model 2}

Transfer station is based on the airport station, the locations of transfer stations and distributions of supply of the medical products depends on medical production demand, delivery time, delivery speed. The distribution of the infection is shown as below:

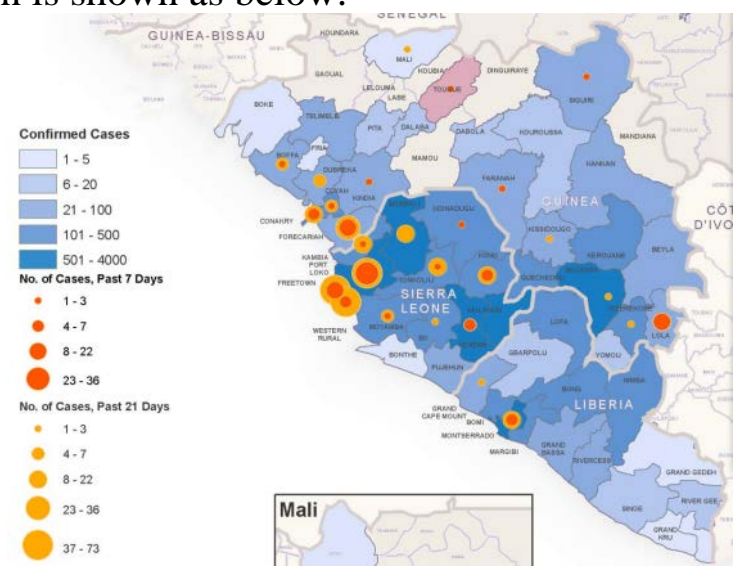

Figure 2 . The distribution of the infection

In consideration of setting up the path road, budget of cost and logistical efficiency are two main factors, thus the short-path method is selected with the program Lingo to make the short-path model, and decide the path road.The distribution of airport stations are shown as below:

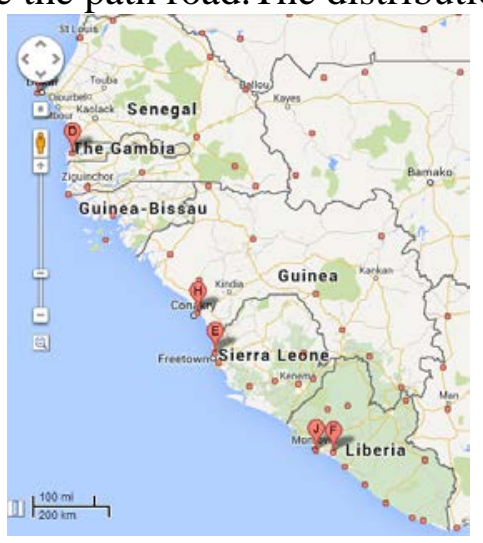

Figure 3 . The distribution of airport stations

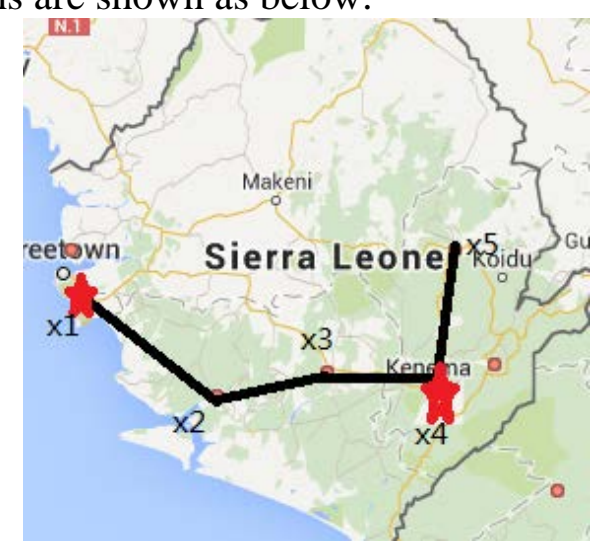

Figure 4 . Sierra leone middle transfer station

Table5.Distance and amount of medical production

\begin{tabular}{|l|l|l|l|l|l|l|}
\hline Distance & $X_{1}$ & $X_{2}$ & $X_{3}$ & $X_{4}$ & $X_{5}$ & Supply \\
\hline$X_{1}$ & 0 & 176 & 268 & 343 & 407 & 7000 \\
\hline$X_{4}$ & 343 & 167 & 75 & 0 & 103 & 8000 \\
\hline Demand & 4000 & 3000 & 2000 & 4000 & 2000 & \\
\hline
\end{tabular}

Table6. Result of medical production distribution

\begin{tabular}{|l|l|l|l|l|l|}
\hline Amount & $Y_{1}$ & $Y_{2}$ & $Y_{3}$ & $Y_{4}$ & $Y_{5}$ \\
\hline$Y_{1}$ & 4000 & 3000 & 0 & 0 & 0 \\
\hline$Y_{4}$ & 0 & 0 & 2000 & 4000 & 2000 \\
\hline
\end{tabular}




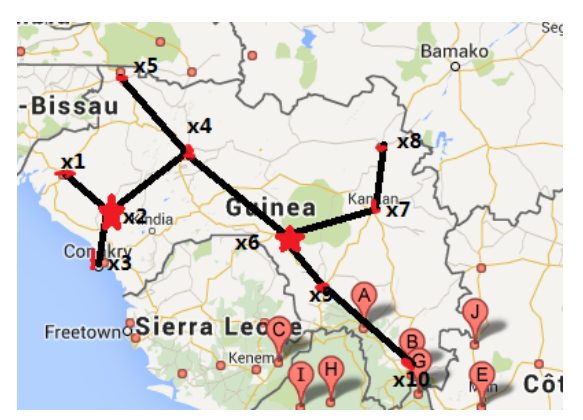

Figure 5 . Guinea middle transfer station

Even though the demand in guinea is relatively lower, but the area is spread and bigger, thus two middle stations are needed.

Table7. Distance and amount of medical production form:

\begin{tabular}{|l|l|l|l|l|l|l|l|l|l|l|l|}
\hline Distance & $X_{1}$ & $X_{2}$ & $X_{3}$ & $X_{4}$ & $X_{5}$ & $X_{6}$ & $X_{7}$ & $X_{8}$ & $X_{9}$ & $X_{10}$ & Supply \\
\hline$X_{2}$ & 102 & 0 & 85 & 180 & 219 & 401 & 571 & 680 & 524 & 742 & 1300 \\
\hline$X_{6}$ & 503 & 401 & 486 & 221 & 260 & 0 & 170 & 280 & 123 & 341 & 2700 \\
\hline Demand & 100 & 500 & 200 & 200 & 300 & 500 & 500 & 200 & 1000 & 500 & \\
\hline
\end{tabular}

\begin{tabular}{|l|l|l|l|l|l|l|l|l|l|l|}
\hline \multicolumn{10}{|c|}{ Table8. Result of medical production distribution: } \\
\hline Amount & $Y_{1}$ & $Y_{2}$ & $Y_{3}$ & $Y_{4}$ & $Y_{5}$ & $Y_{6}$ & $Y_{7}$ & $Y_{8}$ & $Y_{9}$ & $Y_{10}$ \\
\hline$Y_{2}$ & 100 & 500 & 200 & 500 & 0 & 0 & 0 & 0 & 0 & 0 \\
\hline$Y_{6}$ & 0 & 0 & 0 & 0 & 0 & 500 & 700 & 0 & 1500 & 0 \\
\hline$Y_{4}$ & 0 & 0 & 0 & 200 & 300 & 0 & 0 & 0 & 0 & 0 \\
\hline$Y_{7}$ & 0 & 0 & 0 & 0 & 0 & 0 & 500 & 200 & 0 & 0 \\
\hline$Y_{9}$ & 0 & 0 & 0 & 0 & 0 & 0 & 0 & 0 & 1000 & 500 \\
\hline
\end{tabular}

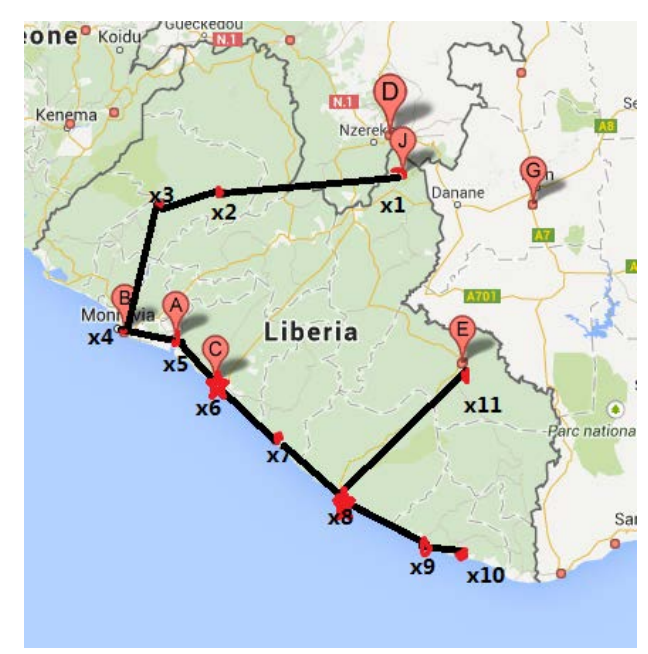

Figure 6 . Liberia middle transfer station

Table9. Distance and amount of medical production form:

\begin{tabular}{|l|l|l|l|l|l|l|l|l|l|l|l|l|}
\hline $\begin{array}{l}\text { Distanc } \\
\mathrm{e}\end{array}$ & $X_{1}$ & $X_{2}$ & $X_{3}$ & $X_{4}$ & $X_{5}$ & $X_{6}$ & $X_{7}$ & $X_{8}$ & $X_{9}$ & $X_{10}$ & $X_{11}$ & $\begin{array}{l}\text { Suppl } \\
\mathrm{y}\end{array}$ \\
\hline$X_{5}$ & 357 & 207 & 153 & 40 & 0 & 48 & 119 & 191 & 271 & 301 & 338 & 8000 \\
\hline$X_{8}$ & 518 & 368 & 314 & 201 & 161 & 113 & 72 & 0 & 80 & 110 & 147 & 1000 \\
\hline $\begin{array}{l}\text { Deman } \\
\mathrm{d}\end{array}$ & 500 & 400 & 100 & 500 & 4000 & 2000 & 500 & 200 & 200 & 200 & 400 & \\
\hline
\end{tabular}


Table10. Result of medical production distribution:

\begin{tabular}{|l|l|l|l|l|l|l|l|l|l|l|l|}
\hline Amount & $Y_{1}$ & $Y_{2}$ & $Y_{3}$ & $Y_{4}$ & $Y_{5}$ & $Y_{6}$ & $Y_{7}$ & $Y_{8}$ & $Y_{9}$ & $Y_{10}$ & $Y_{11}$ \\
\hline$Y_{5}$ & 0 & 0 & 0 & 1500 & 4000 & 2500 & 0 & 0 & 0 & 0 & 0 \\
\hline$Y_{4}$ & 0 & 0 & 1000 & 500 & 0 & 0 & 0 & 0 & 0 & 0 & 0 \\
\hline$Y_{3}$ & 0 & 900 & 100 & 0 & 0 & 0 & 0 & 0 & 0 & 0 & 0 \\
\hline$Y_{2}$ & 500 & 400 & 0 & 0 & 0 & 0 & 0 & 0 & 0 & 0 & 0 \\
\hline$Y_{6}$ & 0 & 0 & 0 & 0 & 0 & 2000 & 500 & 0 & 0 & 0 & 0 \\
\hline$Y_{8}$ & 0 & 0 & 0 & 0 & 0 & 0 & 0 & 200 & 300 & 0 & 500 \\
\hline$Y_{9}$ & 0 & 0 & 0 & 0 & 0 & 0 & 0 & 0 & 100 & 200 & 0 \\
\hline
\end{tabular}

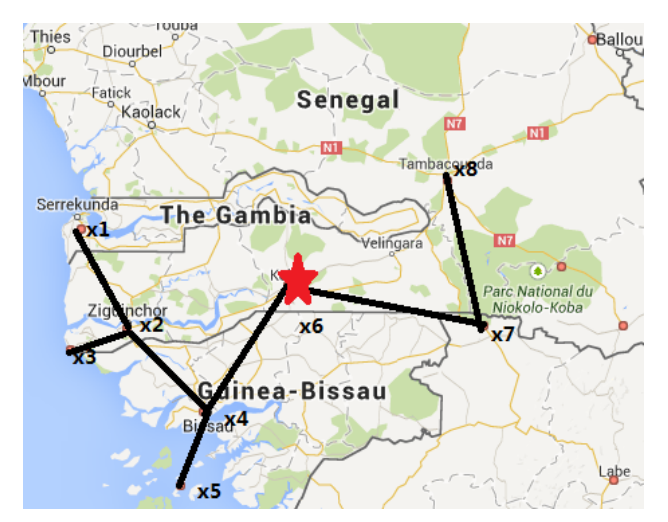

Figure 7 .Middle transfer stations of other areas

Table11. Distance and amount of medical production form:

\begin{tabular}{|l|l|l|l|l|l|l|l|l|l|}
\hline Distance & $X_{1}$ & $X_{2}$ & $X_{3}$ & $X_{4}$ & $X_{5}$ & $X_{6}$ & $X_{7}$ & $X_{8}$ & Supply \\
\hline$X_{4}$ & 193 & 99 & 145 & 0 & 60 & 130 & 298 & 423 & 1200 \\
\hline Demand & 100 & 100 & 100 & 500 & 100 & 100 & 100 & 100 & \\
\hline
\end{tabular}

Table12. Result of medical production distribution

\begin{tabular}{|l|l|l|l|l|l|l|l|l|}
\hline Amount & $Y_{1}$ & $Y_{2}$ & $Y_{3}$ & $Y_{4}$ & $Y_{5}$ & $Y_{6}$ & $Y_{7}$ & $Y_{8}$ \\
\hline$Y_{4}$ & 0 & 300 & 0 & 500 & 100 & 300 & 0 & 0 \\
\hline$Y_{2}$ & 100 & 100 & 100 & 0 & 0 & 0 & 0 & 0 \\
\hline$Y_{6}$ & 0 & 0 & 0 & 0 & 0 & 100 & 200 & 0 \\
\hline$Y_{7}$ & 0 & 0 & 0 & 0 & 0 & 0 & 100 & 100 \\
\hline
\end{tabular}




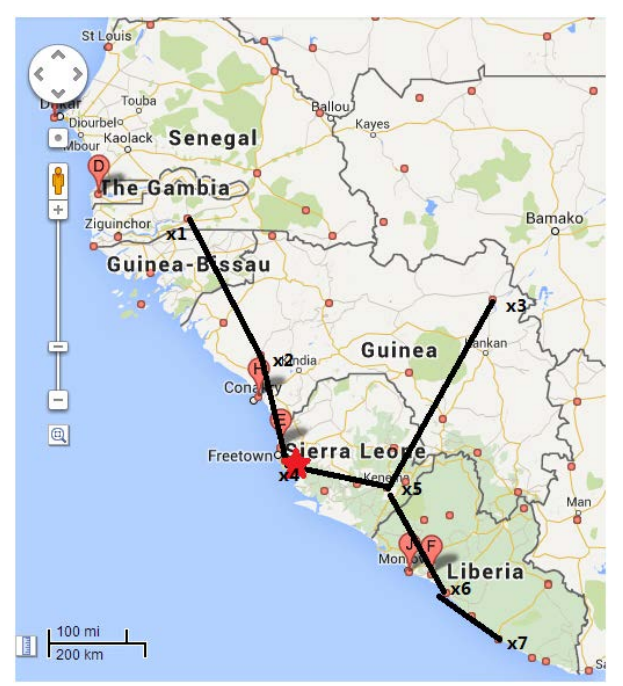

Figure 8 .High transfer station path road

Table13.Distance and amount of medical production form

\begin{tabular}{|l|l|l|l|l|l|l|l|l|}
\hline Distance & $X_{1}$ & $X_{2}$ & $X_{3}$ & $X_{4}$ & $X_{5}$ & $X_{6}$ & $X_{7}$ & Supply \\
\hline$X_{4}$ & 1026 & 487 & 745 & 0 & 310 & 660 & 860 & 29200 \\
\hline Demand & 1200 & 1300 & 2700 & 7000 & 8000 & 8000 & 1000 & \\
\hline
\end{tabular}

Table14.Result of medical production distribution

\begin{tabular}{|l|l|l|l|l|l|l|l|}
\hline Amount & $Y_{1}$ & $Y_{2}$ & $Y_{3}$ & $Y_{4}$ & $Y_{5}$ & $Y_{6}$ & $Y_{7}$ \\
\hline$Y_{4}$ & 0 & 2500 & 0 & 7000 & 19700 & 0 & 0 \\
\hline$Y_{2}$ & 1200 & 1300 & 0 & 0 & 0 & 0 & 0 \\
\hline$Y_{5}$ & 0 & 0 & 2700 & 0 & 8000 & 9000 & 0 \\
\hline$Y_{6}$ & 0 & 0 & 0 & 0 & 0 & 8000 & 1000 \\
\hline
\end{tabular}

Describe model testing and sensitivity analysis.Guinea, Sierra leone and Liberia are the worst-hit areas of the ebola virus infection, in order to achieve the purpose of high efficiency and feasible budget control, the model suggests to set up one high level transfer station for the whole heat area, two middle transfer stations for each country, and small stations for all rest of the airports. The logistical logic is that the middle transfer stations could only receive the medical production from high station, and the small station could only receive the production from middle station. According to the information of resources, the cure medical production would be sent from their manufactures in American and Canada to the high station. It would be much better than directly deliver the production from manufactures to each zone of each countries, not just because of capital resources and budgets but also for realistic flight planning. In this model it is assumed that the high station is built to have the capability to store and deliver huge amount packages. The model would solve the problem that where this station would be located and the path road of delivery.

\section{References}

[1] Marisa C ,Eisenbreg,Joseph N.S Eisenberg,Jeremy P.D silva,Eden V.wells,Deparement of Epidemiology; School of Public Health,University of Michigan,Ann Arbor,*Father Gabriel Richard High School,Ann Arbor;Modeling surveillance and interventions in the 2014 Ebola epidemic;

[2] World Health Organization. Ebola Virus Disease Fact Sheet, updated September 2014. http://www.who.int/mediacentre/factsheets/fs103/en/. 
[3] Roger Ndambi, Philippe Akamituna, Marie-Jo Bonnet, Anicet Mazaya Tukadila, Jean-Jacques Muyembe-Tamfum, and Robert Colebunders. Epidemiologic and Clinical Aspects of the Ebola Virus Epidemic inMosango, Democratic Republic of the Congo, 1995. The Journal of Infectious Diseases, 179:S8 - 10, 1999.

[4] Caitlin M Rivers, Eric T Lofgren, Madhav Marathe, Stephen Eubank, and Bryan L Lewis.Modeling the impact of interventions on an epidemic of ebola in sierra leone and liberia. PLOS Currents Outbreaks, Oct 16, Edition 1, 2014.

[5] Martin I. Meltzer, Charisma Y. Atkins, Scott Santibanez, Barbara Knust, Brett W. Petersen,Elizabeth D. Ervin, Stuart T. Nichol, Inger K. Damon, and Michael L.Washington. Estimatingthe Future Number of Cases in the Ebola Epidemic Liberia and Sierra Leone, 2014-2015.MMWR Surveill Summ, 63:1-14, 2014.

[6] Yao yong. Overall Epidemic Dynamics Equations Existence and Uniqueness [J]. Annals of Mathematics. 1991, 12A(2):218-230.

[7] F. Hoppenstendt. An age-structured epidemic model [J]. J.Franklin Inst. 1994, 197:325-333.

[8] Dan Yamin, Shai Gertler, Martial L. Ndeffo-Mbah, Laura A. Skrip, Mosoka Fallah, Tolbert G. Nyenswah, Frederick L. Altice, Alison P. Galvani. Effect of Ebola Progression on Transmission and Control in Liberia.Annals of Internal Medicine, 2014.

[9] Scott F Dowell, Rose Mukunu, Thomas G Ksiazek, Ali S Khan, Pierre E Rollin, and CJ Peters.Transmission of ebola hemorrhagic fever: a study of risk factors in family members, kikwit,democratic republic of the congo, 1995. Journal of Infectious Diseases, 179(Supplement 1):S87-S91, 1999.

[10] Caitlin M Rivers, Eric T Lofgren, Madhav Marathe, Stephen Eubank, and Bryan L Lewis.Modeling the impact of interventions on an epidemic of ebola in sierra leone and liberia. PLOS Currents Outbreaks, Oct 16, Edition 1, 2014. 